\title{
A Terceirização e seus Impactos: Um Estudo em Grandes Organizações de Minas Gerais
}

\author{
Myrian Constantino de Almeida Valença \\ Allan Claudius Queiroz Barbosa
}

\section{Resumo}

Neste trabalho, realizado junto a três grandes empresas de Minas Gerais dos setores siderúrgico e minerador, procurou-se identificar possíveis impactos causados pelo processo de terceirização na cultura organizacional. Mediante pesquisa qualitativa de natureza descritiva, observou-se que a terceirização está sendo utilizada por essas organizações como estratégia de gestão, como opção de modernização e posicionamento competitivo no contexto atual, e como forma de adequação às necessidades do mercado. Verificou-se, também, que o processo de terceirização poderá gerar perda de identidade nos funcionários da empresa tomadora de serviços e que quanto mais distante do negócio principal da empresa for a atividade terceirizada, menores e pouco significativos serão os problemas para a gestão do processo.

Palavras-chaves: tercerização; cultura organizacional; estratégia de gestão.

\section{Abstract}

The work, done along with three major mining and steel and iron manufacturing companies in Minas Gerais, Brazil, has tried to indentify possible impacts caused by the outsourcing process on the organizational culture. Through qualitative research of descriptive nature, it has been observed that the outsourcing is being used by these organizations in the following ways: as management strategy, as a modernization option and competitive positioning in the current scenario, and as a way of adjustment to the market demands. It has also been observed that the outsourcing process might spun a loss of identity among the employess of the company which is using such services and that the more distant of the company's main business is the outsourced activity, the smallest and less meaninful the problems to the process management.

Key words: outsourcing; organizational culture; management strategy. 


\section{INTRODUÇÃO}

A prática da terceirização não é novidade no mundo dos negócios e está relacionada com a qualidade, a competitividade e a produtividade. Com a terceirização, a empresa concentra-se no seu produto estratégico, naquilo que é capaz de fazer melhor, com competitividade e maior produtividade. As tarefas secundárias e auxiliares são realizadas por empresas que se especializaram de maneira mais racional e com menor custo (Faria, 1994).

Há três propósitos básicos na mente de quem decide terceirizar: a diluição dos custos diretos e indiretos; a elevação do nível de eficiência dessa atividade, pela sua execução terceirizada; e a manutenção de um nível mínimo aceitável de lealdade à empresa, por parte dos novos executores das atividades terceirizadas. Segundo Sá et al. (1997), a terceirização ganha importância em um momento em que as empresas precisam racionalizar recursos, redefinir suas operações, funcionar com estruturas mais enxutas e flexíveis. Assim, ela se apresenta como um dos instrumentos de auxílio à reestruturação organizacional, ao incremento da produtividade e da competitividade e à busca da identidade e comprometimento com a vocação da empresa.

Este aspecto indica, segundo Batista (1994), que um indivíduo que se identifica culturalmente com a organização a que pertence somará esforços para que os objetivos organizacionais sejam alcançados. De maneira inversa, um indivíduo que não se identifica culturalmente com a organização a que pertence ou cuja identidade cultural começa a ser desvirtuada da identidade cultural dos demais membros, começará a desenvolver, consciente ou inconscientemente, esforços cada vez menores ou até mesmo negativos para a consecução dos objetivos organizacionais. Assim, a perda da identidade cultural por parte de determinados membros é um processo negativo para o desenvolvimento da organização.

Para se trabalhar com outra cultura, uma das empresas, ou ambas, têm que efetuar ajustes, baseados nos entendimentos a respeito das suas diferenças culturais. Desse modo, é possível inferir que a terceirização poderá trazer mudanças para a cultura das empresas, podendo-se colocar, ou não, a sobrevivência organizacional em risco ${ }^{(1)}$.

Dentro dessa perspectiva, com base em trabalho de levantamento e análise realizado junto a grandes empresas de Minas Gerais, procurou-se observar de que forma a tercerização tem ressonância nestas organizações, conforme descrito na seqüência. 


\section{Levantamento Preliminar da Terceirização em Grandes Empresas de Minas Gerais}

A partir de empresas classificadas entre as maiores do Estado de Minas Gerais, segundo ranking das revistas Exame Melhores e Maiores (1997) e Conjuntura Econômica (1997), doze delas, representantes dos setores siderúrgico, construção, alimentação, têxtil, mineração e celulose foram mapeadas por meio de questionário fechado, visando a identificar de que forma se encontra o processo de terceirização, bem como os fatores determinantes para a decisão de adotar a estratégia da terceirização, e principais problemas e dificuldades enfrentados neste processo.

Em um segundo momento, foram feitas entrevistas semi-estruturadas com gestores de recursos humanos e responsáveis pela terceirizaçao nas empresas estudadas, além de análise documental, com o objetivo de identificar possíveis impactos da terceirização na empresa, procurando compreender sua cultura organizacional, determinando, assim, dificuldades na gestão do processo ${ }^{(2)}$.

\section{Grau de Tercerização das Atividades}

O primeiro item abordado buscou verificar o quanto as empresas terceirizam suas atividades, por meio da indicação do percentual aproximado de terceirização de cada uma das seguintes atividades: serviços de apoio, serviços de pessoal, serviços de informática, área produtiva, área comercial e área de logística ${ }^{(3)}$.

A Tabela 1, a seguir, apresenta as respostas das empresas pesquisadas quanto ao percentual de terceirização dos serviços de apoio.

A partir dos dados da Tabela 1, percebe-se que as atividades de apoio mais terceirizadas pelas empresas pesquisadas são: remoção de lixo, limpeza, segurança e manutenção. A Tabela 2 apresenta as respostas das empresas pesquisadas quanto ao percentual de terceirização dos seus serviços de pessoal.

As atividades de pessoal mais terceirizadas pelas empresas são as de alimentação e assistência médica e aquelas relacionadas ao recrutamento e seleção e rotinas de seção de pessoal, as menos terceirizadas. 


\section{Tabela 1: Terceirização de Serviços de Apoio}

\begin{tabular}{|c|c|c|c|c|c|c|c|c|c|c|}
\hline & \multicolumn{7}{|c|}{ PERCENTUALDE TERCEIRIZAÇ̃̃O DAS ATIVIDADES DE APOIO (\%) } \\
\cline { 2 - 12 } EMPRESA & $\begin{array}{c}\text { Remoção } \\
\text { de } \\
\text { lixo }\end{array}$ & Limpeza & $\begin{array}{c}\text { Seg. } \\
\text { patri- } \\
\text { monial }\end{array}$ & $\begin{array}{c}\text { Manu- } \\
\text { tenção } \\
\text { predial }\end{array}$ & $\begin{array}{c}\text { Serv. } \\
\text { jurí- } \\
\text { dicos }\end{array}$ & $\begin{array}{c}\text { Servi- } \\
\text { ços } \\
\text { gerais }\end{array}$ & $\begin{array}{c}\text { Serv. } \\
\text { de Co- } \\
\text { brança }\end{array}$ & $\begin{array}{c}\text { Compras } \\
\text { não pro- } \\
\text { dutivas }\end{array}$ & $\begin{array}{c}\text { Conta- } \\
\text { bilidade }\end{array}$ & $\begin{array}{c}\text { Grau } \\
\text { de ter- } \\
\text { ceirização* }\end{array}$ \\
\hline 1 & 0 & 100 & 100 & 100 & 0 & 0 & 10 & 0 & 0 & 34,4 \\
\hline 2 & 100 & 100 & 0 & 10 & 0 & 50 & 0 & 0 & 0 & 28,8 \\
\hline 3 & 100 & 100 & 100 & 0 & 50 & 95 & 0 & 0 & 0 & 49,4 \\
\hline 4 & 100 & 100 & 50 & 80 & 0 & 0 & 0 & 0 & 0 & 36,6 \\
\hline 5 & 100 & 100 & 100 & 100 & 80 & 50 & 0 & 100 & 0 & 70,0 \\
\hline 6 & 0 & 0 & 0 & 0 & 100 & 0 & 100 & 0 & 0 & 22,2 \\
\hline 7 & 0 & 100 & 100 & 0 & 0 & 0 & 0 & 0 & 0 & 22,2 \\
\hline 8 & 100 & 100 & 100 & 100 & 20 & 85 & 0 & 0 & 15 & 57,7 \\
\hline 9 & 100 & 100 & 0 & 100 & 30 & 70 & 100 & 0 & 0 & 55,5 \\
\hline 10 & 100 & 100 & 100 & 100 & 70 & 80 & 0 & 0 & 0 & 61,1 \\
\hline 11 & 100 & 100 & 05 & 100 & 15 & 100 & 0 & 0 & 0 & 46,6 \\
\hline 12 & 100 & 100 & 0 & 100 & 75 & 0 & 0 & 0 & 0 & 41,6 \\
\hline
\end{tabular}

Fonte: levantamento feito pelos autores.

* Média aritmética dos percentuais por empresa para a terceirização das atividades de apoio.

Tabela 2: Terceirização dos Serviços de Pessoal

\begin{tabular}{|c|c|c|c|c|c|c|}
\hline \multirow{2}{*}{ EMPRESA } & \multicolumn{6}{|c|}{ PERCENTUAL DE TERCEIRIZAÇÃO DAS ATIVIDADES DE PESSOAL (\%) } \\
\cline { 2 - 7 } & Restaurante & $\begin{array}{c}\text { Transporte } \\
\text { de pessoal }\end{array}$ & $\begin{array}{c}\text { Assistência } \\
\text { médica }\end{array}$ & $\begin{array}{c}\text { Recrutamento } \\
\text { e seleção }\end{array}$ & $\begin{array}{c}\text { Rotina de } \\
\text { depto. } \\
\text { pessoal }\end{array}$ & $\begin{array}{c}\text { Grau de } \\
\text { terceiri- } \\
\text { zação * }\end{array}$ \\
\hline 1 & 100 & 100 & 100 & 100 & 100 & 100,0 \\
\hline 2 & 100 & 0 & 0 & 100 & 0 & 40,0 \\
\hline 3 & 100 & 100 & 0 & 0 & 0 & 40,0 \\
\hline 4 & 100 & 0 & 0 & 0 & 0 & 20,0 \\
\hline 5 & 100 & 100 & 100 & 0 & 0 & 60,0 \\
\hline 6 & 0 & 0 & 100 & 0 & 0 & 20,0 \\
\hline 7 & 100 & 0 & 100 & 0 & 0 & 40,0 \\
\hline 8 & 100 & 95 & 100 & 10 & 0 & 61,0 \\
\hline 9 & 100 & 0 & 100 & 100 & 0 & 60,0 \\
\hline 10 & 100 & 100 & 0 & 0 & 0 & 40,0 \\
\hline 11 & 100 & 100 & 95 & 05 & 0 & 60,0 \\
\hline 12 & 0 & 0 & 0 & 100 & 0 & 20,0 \\
\hline
\end{tabular}

Fonte: levantamento feito pelos autores.

* Média aritmética dos percentuais de terceirização por empresa das atividades de pessoal.

A representatividade da terceirização dos serviços de informática não pode ser considerada muito grande, embora seja uma tendência cada vez maior por parte das empresas terceirizá-los. A Tabela 3 apresenta esses resultados. 
Tabela 3: Terceirização dos Serviços de Informática

\begin{tabular}{|c|c|c|c|c|c|c|c|}
\hline \multirow{2}{*}{ EMPRESA } & \multicolumn{6}{|c|}{ PERCENTUAL DE TERCEIRIZAÇÃO DOS SERVIÇOS DE INFORMÁTICA (\%) } \\
\cline { 2 - 8 } & $\begin{array}{c}\text { Progra- } \\
\text { mação }\end{array}$ & $\begin{array}{c}\text { Suporte } \\
\text { técnico }\end{array}$ & $\begin{array}{c}\text { Análise de } \\
\text { sistemas }\end{array}$ & $\begin{array}{c}\text { Micro- } \\
\text { informá- } \\
\text { tica }\end{array}$ & $\begin{array}{c}\text { Operação/ } \\
\text { processa- } \\
\text { mento }\end{array}$ & $\begin{array}{c}\text { Operação/ } \\
\text { opera- } \\
\text { dores }\end{array}$ & $\begin{array}{c}\text { Grau de } \\
\text { terceiri- } \\
\text { zação * }\end{array}$ \\
\hline 1 & 100 & 0 & 100 & 100 & 0 & 0 & 50,0 \\
\hline 2 & 20 & 30 & 0 & 0 & 0 & 0 & 8,3 \\
\hline 3 & 0 & 0 & 0 & 0 & 0 & 0 & 0,0 \\
\hline 4 & 0 & 0 & 0 & 0 & 0 & 0 & 0,0 \\
\hline 5 & 0 & 0 & 0 & 0 & 0 & 0 & 0,0 \\
\hline 6 & 0 & 0 & 0 & 0 & 0 & 0 & 0,0 \\
\hline 7 & 100 & 100 & 100 & 0 & 0 & 0 & 50,0 \\
\hline 8 & 100 & 20 & 100 & 20 & 100 & 100 & 73,3 \\
\hline 9 & 100 & 100 & 100 & 100 & 100 & 100 & 100,0 \\
\hline 10 & 20 & 0 & 0 & 0 & 0 & 0 & 3,3 \\
\hline 11 & 05 & 0 & 05 & 0 & 0 & 0 & 1,6 \\
\hline 12 & 0 & 0 & 0 & 0 & 0 & 0 & 0,0 \\
\hline
\end{tabular}

Fonte: levantamento feito pelos autores.

* Média aritmética dos percentuais de terceirização por empresa dos serviços de informática.

A terceirização de atividades da área produtiva é ainda muito pequena e pouco explorada pelas empresas, conforme pode ser observado na Tabela 4.

\section{Tabela 4: Terceirização da Área Produtiva}

\begin{tabular}{|c|c|c|c|c|}
\hline \multirow{2}{*}{ EMPRESA } & \multicolumn{3}{|c|}{ PERCENTUAL DERCEIRIZAÇÃO DAS ATIVIDADES DAÁREA PRODUTIVA(\%) } \\
\cline { 2 - 5 } & $\begin{array}{c}\text { Manutenção } \\
\text { industrial }\end{array}$ & $\begin{array}{c}\text { Atividades acessórias } \\
\text { à produção }\end{array}$ & $\begin{array}{c}\text { Atividades produ- } \\
\text { tivas principais }\end{array}$ & $\begin{array}{c}\text { Grau de } \\
\text { terceirização* }\end{array}$ \\
\hline 1 & 0 & 0 & 0 & 0,0 \\
\hline 2 & 0 & 0 & 0 & 0,0 \\
\hline 3 & 0 & 0 & 0 & 0,0 \\
\hline 4 & 0 & 0 & 0 & 0,0 \\
\hline 5 & 0 & 0 & 0 & 0,0 \\
\hline 6 & 0 & 0 & 10 & 0,0 \\
\hline 7 & 20 & 20 & 0 & 16,6 \\
\hline 8 & 0 & 0 & 0 & 0,0 \\
\hline 9 & 60 & 30 & 0 & 30,0 \\
\hline 10 & 30 & 65 & 0 & 31,6 \\
\hline 11 & 0 & 0 & 0,0 \\
\hline 12 & 0 & & 0 & 0 \\
\hline
\end{tabular}

Fonte: levantamento feito pelos autores.

* Média aritmética dos percentuais de terceirização por empresa das atividades da área produtiva. 
A área comercial apresenta o menor índice de terceirização nas empresas pesquisadas. Tal constatação pode ser verificada na Tabela 5.

\section{Tabela 5: Terceirização das Atividades da Área Comercial}

\begin{tabular}{|c|c|c|c|c|c|}
\hline \multirow{2}{*}{ EMPRESA } & \multicolumn{5}{|c|}{ PERCENTUAL DE TERCEIRIZAÇÃo DAS ATIVIDADES DAÁREA COMERCIAL (\%) } \\
\cline { 2 - 6 } & $\begin{array}{c}\text { Vendas a } \\
\text { clientes }\end{array}$ & $\begin{array}{c}\text { Assistência } \\
\text { técnica }\end{array}$ & $\begin{array}{c}\text { Serviços de } \\
\text { telemarketing }\end{array}$ & $\begin{array}{c}\text { Serviços de aten- } \\
\text { dimento a clientes }\end{array}$ & $\begin{array}{c}\text { Grau de tercei- } \\
\text { rização* }\end{array}$ \\
\hline 1 & 0 & 0 & 0 & 0 & 0,0 \\
\hline 2 & 0 & 0 & 0 & 0 & 0,0 \\
\hline 3 & 0 & 0 & 0 & 50 & 12,6 \\
\hline 4 & 0 & 0 & 0 & 0 & 0,0 \\
\hline 5 & 0 & 0 & 0 & 0 & 0,0 \\
\hline 6 & 15 & 0 & 0 & 0 & 3,75 \\
\hline 7 & 0 & 0 & 0 & 0 & 0,0 \\
\hline 8 & 0 & 0 & 0 & 0 & 0,0 \\
\hline 9 & 0 & 0 & 0 & 0 & 0,0 \\
\hline 10 & 0 & 0 & 0 & 0 & 0,0 \\
\hline 11 & 0 & 0 & 0 & 0 & 0,0 \\
\hline 12 & 0 & 0 & 0 & 0 & 0,0 \\
\hline
\end{tabular}

Fonte: levantamento feito pelos autores.

* Média aritimética dos percentuais de terceirização por empresa das atividades da área comercial.

As atividades de logística mais terceirizadas, mesmo pouco representativas, dizem respeito ao transporte e distribuição de produtos, conforme a Tabela 6.

\section{Tabela 6: Terceirização da Área de Logística}

\begin{tabular}{|c|c|c|c|c|c|}
\hline \multirow{2}{*}{ EMPRESA } & \multicolumn{5}{|c|}{ PERCENTUAL DE TERCEIRIZAÇãO DAS ATIVIDADES DAÁREADE LOGíSTICA(\%) } \\
\cline { 2 - 6 } & $\begin{array}{c}\text { Distribuição } \\
\text { física de produ- } \\
\text { tos a clientes }\end{array}$ & $\begin{array}{c}\text { Serviços de } \\
\text { carga e } \\
\text { descarga }\end{array}$ & $\begin{array}{c}\text { Armaze- } \\
\text { nagem }\end{array}$ & $\begin{array}{c}\text { Movimentação } \\
\text { interna de materiais } \\
\text { e produtos }\end{array}$ & $\begin{array}{c}\text { Grau de } \\
\text { terceiri- } \\
\text { zação* }\end{array}$ \\
\hline 1 & 100 & 50 & 0 & 0 & 37,5 \\
\hline 2 & 0 & 0 & 0 & 0 & 0,0 \\
\hline 3 & 0 & 0 & 0 & 0 & 0,0 \\
\hline 4 & 0 & 100 & 0 & 100 & 50,0 \\
\hline 5 & 100 & 100 & 100 & 30 & 82,5 \\
\hline 6 & 0 & 0 & 0 & 0 & 0,0 \\
\hline 7 & 0 & 0 & 0 & 0 & 0,0 \\
\hline 8 & 100 & 100 & 0 & 0 & 50,0 \\
\hline 9 & 100 & 0 & 0 & 30 & 32,5 \\
\hline 10 & 0 & 0 & 0 & 0 & 0,0 \\
\hline 11 & 100 & 100 & 100 & 100 & 100,0 \\
\hline 12 & 0 & 0 & 0 & 0 & 0,0 \\
\hline
\end{tabular}

Fonte: levantamento feito pelos autores.

* Média aritmética dos percentuais de terceirização por empresa das atividades da área de logística. 
A partir do levantamento e análise dos dados anteriormente vistos, verifica-se uma tendência maior de terceirização das atividades não relacionadas à área produtiva ou ao core business das empresas.

\section{Fatores Determinantes na Terceirização}

O segundo aspecto deste mapeamento procurou identificar os principais fatores determinantes da decisão de adotar a terceirização das atividades. As opções foram numeradas pela importância (atribuindo-se o número 1 para o motivo principal e 9 para o menos determinante). As respostas foram dadas a partir das seguintes opções para terceirizar: (a) seguir visão estratégica no sentido de concentrar toda a atenção no próprio negócio; (b) redução de custos; (c) simplificação do processo operacional; (d) aumentar a capacidade produtiva da empresa, utilizando-se de recursos disponíveis em terceiros; (e) utilizar melhor o tempo e a energia do pessoal da empresa; (f) disponibilidade de fornecedor especializado na atividade; (g) respostas mais rápidas às variações de demanda; (h) indisponibilidade de competência técnica; (i) outras.

Essas opções podem ser divididas em dois grupos:

. Decisão baseada em objetivos de concentração no negócio principal da empresa, representada pelas opções a, e, f, h.

. Decisão baseada em objetivos de redução de custos, representada pelas opções b, c, d, g.

Na Tabela 7 estão apresentadas as respostas das empresas.

Observou-se que há, por parte das empresas, uma preocupação maior com os objetivos estratégicos ao decidir terceirizar suas atividades, uma vez que os principais fatores determinantes da decisão de terceirização são: seguir visão estratégica e existência de fornecedor especializado na área. Além disso, o problema não está na capacidade técnica de a empresa realizar o serviço, mas no desejo de recorrer à terceirização como opção de modernizar e investir, no sentido de tornar a organização mais competitiva. 


\section{Tabela 7: Fatores de Decisão para Terceirização}

\begin{tabular}{|c|c|c|c|c|c|c|c|c|c|c|c|c|}
\hline Fator de Decisão & \multicolumn{12}{|c|}{ E M P R E S S } \\
\hline $\begin{array}{r}\text { Grau } \\
\text { Importância }\end{array}$ & 1 & 2 & 3 & 4 & 5 & 6 & 7 & 8 & 9 & 10 & 11 & 12 \\
\hline $\begin{array}{l}\text { Seguir visão } \\
\text { estratégica }\end{array}$ & 1 & 1 & 1 & 1 & 1 & 4 & 6 & 1 & 1 & 1 & 1 & $\mathrm{NR}^{*}$ \\
\hline Redução de custos & 3 & 3 & 2 & 5 & 2 & 6 & 5 & 4 & 5 & 3 & 4 & NR \\
\hline $\begin{array}{l}\text { Simplificação do } \\
\text { processo operacional }\end{array}$ & & 2 & 6 & 1 & 9 & 5 & 2 & 5 & 6 & 5 & 3 & NR \\
\hline $\begin{array}{l}\text { Aumentar a capacidade } \\
\text { produtiva da empresa }\end{array}$ & 6 & 7 & 5 & 2 & 8 & 9 & 3 & 6 & 7 & 2 & 2 & NR \\
\hline $\begin{array}{l}\text { Otimização do tempo } \\
\text { e da energia do pessoal }\end{array}$ & 8 & 6 & 3 & 1 & 2 & 8 & 7 & 2 & 2 & 4 & 5 & NR \\
\hline $\begin{array}{l}\text { Disponibilidade de } \\
\text { fornecedor } \\
\text { especializado }\end{array}$ & 2 & 5 & 4 & 2 & 3 & 1 & 4 & 3 & 3 & 6 & 6 & NR \\
\hline $\begin{array}{l}\text { Respostas mais } \\
\text { rápidas às variações } \\
\text { de demanda }\end{array}$ & 7 & 4 & 7 & 3 & 2 & 3 & 7 & 7 & 4 & 7 & 7 & NR \\
\hline $\begin{array}{l}\text { Indisponibilidade } \\
\text { de competência } \\
\text { técnica }\end{array}$ & 5 & 8 & 8 & 9 & 7 & 2 & 1 & 8 & 8 & 8 & 8 & NR \\
\hline Outras & & & & & & 7 & & & & & & \\
\hline
\end{tabular}

Fonte: levantamento de dados feito pelos autores.

*NR: Não respondeu.

A segunda parte desta questão procurou saber se as empresas alcançaram os objetivos propostos ao adotarem a terceirização. O resultado pode ser observado no Quadro 1 a seguir.

\section{Quadro 1: Alcance dos Objetivos com a Terceirização}

\begin{tabular}{|c|c|c|c|c|c|c|c|c|c|}
\hline \multicolumn{9}{|c|}{ OBJETIVO } & I \\
\hline EMPRESA & A & B & C & D & E & F & G & H & I \\
\hline $\mathbf{1}$ & & & & & & & X & X & \\
\hline $\mathbf{2}$ & & & & & & & & & \\
\hline $\mathbf{3}$ & & & & & & & & & \\
\hline $\mathbf{5}$ & & & & & & & & X & \\
\hline $\mathbf{6}$ & & & $\mathrm{X}$ & $\mathrm{X}$ & & & & $\mathrm{X}$ & \\
\hline $\mathbf{7}$ & - & - & - & - & - & - & - & - & - \\
\hline $\mathbf{8}$ & & $\mathrm{X}$ & & & & & & $\mathrm{X}$ & \\
\hline $\mathbf{9}$ & & & & & & & & & \\
\hline $\mathbf{1 1}$ & & & $\mathrm{X}$ & & & & & & \\
\hline $\mathbf{1 2}$ & & & $\mathrm{X}$ & & & $\mathrm{X}$ & & & \\
\hline
\end{tabular}




\section{Problemas Decorrentes do Processo de Terceirização}

Os principais problemas enfrentados pelas empresas na adoção da terceirização de atividades, podem ser subdivididos em:

- Problemas relacionados à prestação do serviço pelos terceiros: opções a, c, d.

- Problemas de relacionamento entre os terceiros e os funcionários da empresa: opções b, e, f.

Sendo que:

a.Distanciamento entre as necessidades e expectativas da empresa daquilo que tem sido oferecido pelos terceiros.

b.Dificuldade em estabelecer relação de parceria com os terceiros.

c. Gasto de muito tempo e energia na gestão da rede de fornecedores e serviços terceirizados.

d.Menor capacidade técnica dos terceiros.

e.Choque cultural entre os terceiros e funcionários que já trabalham na empresa.

f. Problemas de relacionamento entre os funcionários da empresa e os terceiros.

g.Outros.

Pediu-se que fosse identificado o problema principal, assinalando-o com o número 1 e, assim, sucessivamente, até o número 7, como o problema menos relevante enfrentado pela empresa com a estratégia da terceirização.

A Tabela 8 resume o que foi respondido pelas empresas quanto aos problemas enfrentados a partir da adoção da terceirização.

A partir desses resultados, pode-se dizer que há certa homogeneidade quanto aos problemas enfrentados, com pequeno destaque para as questões relacionadas à prestação de serviços pelos terceiros. As empresas que mais têm problemas de relacionamento entre terceiros e funcionários são as empresas 5 e 9. No que diz respeito à prestação de serviços dos terceiros, as empresas que mais enfrentaram problemas foram 1, 5 e 7. Há um distanciamento entre as necessidades e expectativas das empresas e aquilo que tem sido oferecido pelos terceiros, determinando uma dificuldade em estabelecer relação de parceria com esses, o que acarreta um dispêndio de tempo e energia na gestão desses contratos. 
Tabela 8: Problemas Decorrentes da Terceirização

\begin{tabular}{|c|c|c|c|c|c|c|c|c|c|c|c|c|}
\hline & \multicolumn{12}{|c|}{ EMPRESA } \\
\hline $\begin{array}{l}\text { PROBLEMA } \\
\text { Grau de Importância }\end{array}$ & 1 & 2 & 3 & 4 & 5 & 6 & 7 & 8 & 9 & 10 & 11 & 12 \\
\hline $\begin{array}{c}\text { Disparidade entre as necessidades } \\
\text { e expectativas da empresa e o que } \\
\text { é oferecido pelos terceiros }\end{array}$ & 3 & 2 & NR & 3 & 1 & 5 & 1 & 3 & 3 & 2 & 5 & $\mathrm{NR}^{*}$ \\
\hline $\begin{array}{l}\text { Dificuldade em estabelecer } \\
\text { relação de parceria c/ terceiros }\end{array}$ & 4 & 5 & NR & 1 & 2 & 2 & 4 & 4 & 1 & 1 & 6 & NR \\
\hline $\begin{array}{l}\text { Gasto de muito tempo e energia } \\
\text { na gestão da terceirização }\end{array}$ & 2 & 6 & NR & 4 & 2 & 1 & 2 & 2 & 5 & 4 & 1 & NR \\
\hline $\begin{array}{c}\text { Menor capacidade técnica dos } \\
\text { terceiros }\end{array}$ & 1 & 1 & NR & 2 & 3 & 4 & 3 & 6 & 4 & 5 & 4 & NR \\
\hline $\begin{array}{l}\text { Choque cultural entre os terceiros } \\
\text { e funcionários da empresa }\end{array}$ & 5 & 3 & NR & 5 & 2 & 6 & 5 & & 2 & 3 & 2 & NR \\
\hline $\begin{array}{l}\text { Problemas de relacionamento } \\
\text { entre os funcionários da empresa } \\
\text { e os terceiros }\end{array}$ & 6 & 4 & NR & 6 & 6 & 3 & 6 & 5 & 6 & 6 & 3 & NR \\
\hline Outros & & & NR & & & 7 & 7 & 7 & & & & NR \\
\hline
\end{tabular}

Fonte: levantamento de dados feito pelos autores

* NR: Não respondeu.

\section{Riscos e Avaliação da Terceirização}

Na $4^{\mathrm{a}}$ questão, perguntou-se se os problemas enfrentados pelas empresas podem colocar em risco os objetivos que tinham ao adotar a estratégia da terceirização. Para as empresas 9 e 10, existe algum risco. Para as demais, os problemas decorrentes da terceirização não constituem ameaça aos seus objetivos iniciais ao terceirizar algumas de suas atividades.

Na questão número 5, solicitou-se que se avaliasse a terceirização e o que poderia ser feito para melhorar o processo. Os resultados indicados demonstram que 6 empresas consideram positiva (empresas 1, 2, 3, 6, 8, 9), uma delas considera negativa (10), a empresa 7 considera que a terceirização atende às expectativas, duas estão vivendo um momento de transição (4 e 11) e duas não sabem (5 e 12).

\section{Seleção das Empresas para Análise dos Impactos da Terceirização}

De posse dos dados obtidos junto às doze empresas pesquisadas na primeira etapa, foram definidos os seguintes critérios para a definição das que seriam objeto de investigação dos impactos da terceirização na cultura organizacional e que determinaram dificuldades na gestão do processo:

. Empresas que mais terceirizaram suas atividades: 1, 5, 8, 9, 10 e 11. 
. Empresas que mais enfrentaram problemas de relacionamento entre funcionários da tomadora de serviços e terceirizadas: 5 e 9.

- Empresas que menos atingiram os objetivos determinantes da terceirização de suas atividades: $1,4,5$, 8 e 11 .

. Empresas que acreditaram na existência de riscos ao terceirizar suas atividades: 9 e 10.

Esses resultados levaram à realização de uma investigação mais aprofundada da terceirização nas empresas 1 , 5, 8, 9, 10 e $11^{(4)}$, que são representantes de setores básicos da economia mineira: celulose, minerais não-metálicos, mineração e siderurgia.

Desse modo, a segunda etapa do estudo, que constou de entrevistas semiestruturadas e análise documental, foi realizada nas empresas representadas pelos números 10, 11 e 8, que serão denominadas como A, B e C, respectivamente.

\section{Impacto da Terceirização: Apresentação dos Resultados Encontrados}

Nesta etapa do trabalho, buscou-se conhecer o processo de terceirização das empresas representantes do setor siderúrgico e minerador, sua cultura organizacional e os possíveis impactos dessa estratégia de gestão. Foram realizadas entrevistas semi-estruturadas ${ }^{(5)}$ com profissionais que ocupam cargos-chaves nas empresas, ligados à gestão da terceirização. Além disso, realizou-se, também, análise de documentos, folhetos, manuais e filmes institucionais das empresas pesquisadas.

\section{A Empresa A}

Iniciando suas atividades em 1977, a empresa A ocupa posição de destaque entre as principais fornecedoras de pelotas de minério de ferro para o mercado siderúrgico mundial. Em meados da década de 80, após atravessar várias situações de crise, voltou a crescer e é atualmente uma empresa com grande representatividade no setor. Mantém unidades industriais em dois Estados brasileiros e seu controle acionário pertence a dois grupos, sendo um deles estrangeiro.

Segundo material institucional divulgado pela empresa, seus valores e objetivos para a satisfação dos interesses de seus acionistas são: satisfazer às necessida- 
des de seus clientes e tornar-se fornecedora preferencial; promover a iniciativa, a criatividade, a competência técnica e gerencial e a permanente melhoria em todos os seus níveis e setores; adotar os mais altos padrões éticos em todos os seus negócios; operar, quanto possível, com os níveis mais elevados de qualidade, produtividade e lucratividade, buscando a permanente atualização tecnológica; assegurar aos seus empregados um ambiente de trabalho estável e seguro, proporcionando o mais alto nível de satisfação, compatível com os objetivos da empresa e com as condições econômicas do país; ampliar seus negócios com ativos de elevada qualidade e rentabilidade; conciliar o desenvolvimento das suas atividades com a proteção responsável do meio ambiente, mantendo a sua integração nas comunidades onde atua.

A empresa possuía, em maio de 1998, 769 terceirizados e um total de 1.449 empregados. Seu processo de terceirização iniciou-se em 1991, pelos serviços de apoio (restaurante, conservação e limpeza e transporte de pessoal) e, a partir de 1993, com o serviço de vigilância. A gestão da terceirização na empresa A é realizada pela Área de Serviços Contratados, subordinada à Diretoria Financeira. Esse setor trabalha regido por um manual que contém diretrizes e um modelo de gestão para serviços contratados. São feitos relatórios mensais e auditorias periódicas, baseadas na verificação de itens de controle e gestão da qualidade total. Cada contrato é gerido por um gerente que representa a área que recebe os serviços.

A ligação da Área de Serviços Contratados com a Diretoria Financeira leva à constatação do foco econômico/financeiro com que é tratada a terceirização na empresa:

“Em toda terceirização você analisa a questão de custo. À medida que a parceria vai melhorando e os serviços vão desenvolvendo, os custos realmente estão baixando" (assessor de serviços contratados).

Os principais impactos causados pelo processo foram, entre outros, redução de custos, perda de condições de trabalho antes existentes, medo de demissão e choque de culturas.

“Teve impacto de medo, de clima de demissão, de sair de uma empresa de determinado porte para uma empresa de um porte menor, com perda de benefícios, choque de culturas [muitos empregados da empresa vêem os empregados da contratada como subalternos, principalmente se a terceirização é de alguma atividade que era feita pela empresa]” (assessor de serviços contratados). 
Observou-se um descompasso em relação ao padrão cultural da empresa de favorecer os empregados em um ambiente estável e seguro; no entanto, segundo os informantes, por outro lado, ela está em busca da garantia da sua lucratividade e produtividade. Além disso, foi destacada a questão da maior facilidade de gestão da terceirização de atividades que não fazem parte do core business da empresa. Para que o processo seja melhorado, foram indicados pontos como os seguintes: fazer uma interface da área que solicita o serviço com a que o recebe e a própria empresa, visando a gerenciar conflitos; igualar a qualificação e condição de trabalho do contratado e perder o foco no custo.

Nessa empresa, houve, por parte dos entrevistados, certa dificuldade de conceituar cultura organizacional. Para o assessor de recursos humanos, ela é o "somatório de uma série de fatores que formam o jeito de conduzir próprio daquela organização. São os costumes que geram a relação de tratar dos assuntos”.

Os aspectos preconizados pela empresa por meio dos seus objetivos determinam os seus padrões culturais, como foco no cliente, valorização da iniciativa, criatividade e competência, ética, qualidade, produtividade, lucratividade, ambiente de trabalho estável e seguro, proteção ambiental e integração com a comunidade.

Quanto aos impactos da terceirização na cultura da empresa, destacam-se: a necessidade de ajuste das normas e procedimentos internos, nova relação de trabalho e ameaça ao valor do "emprego seguro e estável”.

"A presença de pessoas de fora, novas formas de enxergar o mundo, de enfrentar os problemas, contribui para que a pessoa se abra um pouco mais. Logicamente, algumas normas, alguns procedimentos internos têm que ser adequados para receber essas pessoas que ficam permanentemente prestando serviço na empresa” (assessor de serviços contratados).

“Afetou o ambiente no sentido em que as pessoas passavam a não se sentir tão seguras, tão estáveis como se sentiam antes. Um elemento novo, uma nova relação de trabalho estava sendo introduzida e uma forma diferente de gerenciamento também estava sendo introduzida” (assessor de recursos humanos).

Segundo os entrevistados, existe uma tendência de os contratados assimilarem a cultura da empresa e sua tecnologia/know how de trabalho. Foram identificados nessa empresa preocupação e investimentos no desenvolvimento de parceria com os contratados, uma vez que foi criada uma estrutura própria para gerenciar o processo de terceirização. 
Apesar da dificuldade de um dos entrevistados identificar e perceber a cultura organizacional, pode-se dizer que a empresa passou por significativo processo de mudança nesse sentido, devido à implantação do Programa de Qualidade Total, que por si só carrega um modelo e método de trabalho que precisam ser incorporados aos aspectos da cultura organizacional para funcionarem adequadamente.

Assim, percebe-se que não é só a terceirização que afeta a cultura da empresa, mas também as outras estratégias de gestão que vêm sendo adotadas por ela.

\section{A Empresa B}

Fundada em abril de 1956 e inaugurada em 1962, a empresa B representa o setor siderúrgico. Nasceu de uma associação entre o Governo Federal, o Estadual e um grupo estrangeiro. Dessa associação, surgiram os primeiros valores que orientaram a sua construção e inspiraram os seus fundadores, sendo preservados e desenvolvidos ao longo da sua história: sentido de trabalho em equipe, conhecimento tecnológico, busca contínua por melhores resultados, estímulo permanente à educação, treinamento dos funcionários, tradição familiar, simplicidade e humildade para olhar de frente os próprios erros e a mineiridade ${ }^{(6)}$.

A empresa possuía, em maio de 1998, 8.850 empregados e 5.668 terceirizados, totalizando 14.418 empregados. A terceirização faz parte do leque de mudanças propostas para a sua modernização pós-privatização, buscando o processo de melhoria da eficácia organizacional e funcional, com o objetivo de simplificar processos administrativos, aumentar a produtividade e racionalizar a estrutura.

O processo de terceirização na empresa, segundo os entrevistados, foi lento e gradual e iniciou-se com serviços de apoio (limpeza, gráfica, alimentação), embalagem de produto, expedição e transporte. Ele é gerido pelas áreas usuárias, que procuram discutir o contrato de terceirização com o setor específico da empresa. A área de negócios/usuária possui uma pessoa chamada fiscal de contrato, que intermedia os interesses da empresa e o contrato próprio e cada diretoria controla o seu pessoal terceirizado/contratado.

Quanto aos impactos causados pelo processo, os entrevistados, de maneira geral, indicam que foi pouco traumático, uma vez que, na maioria das vezes, a experiência da empresa foi de terceirizar para ex-empregados, principalmente aposentados; no entanto existem indícios de que, no início do processo, as pessoas apresentem um nível maior de resistência:

"No momento que você está planejando, tem uma resistência muito grande, porque, às vezes, existe a mudança do status quo” (gerente de O\&M). 
No que diz respeito ao que poderia ser feito para melhorar o processo de terceirização, os entrevistados indicaram: pesquisar a satisfação do cliente, estabelecer parceria com as empresas, estreitar as relações e conseguir fiscalizar mais diretamente o serviço prestado. Fazer com que os terceiros acompanhem as tendências da empresa, procurar manter a integração entre os efetivos e os terceiros e mudanças na legislação também foram destacados.

A cultura da organização é amplamente difundida e desde o momento em que se chega à empresa, são percebidos alguns de seus traços. Ela é conceituada genericamente como:

“Conjunto de comportamentos, de normas, que sejam explícitas ou implícitas, de valores que refletem todas as interações, o relacionamento entre as pessoas na organização, as respostas frente aos desafios” (gerente de O\&M).

Segundo documento de circulação da empresa, os seus principais pressupostos básicos, que ao longo do tempo vêm constituindo a sua cultura, são: respeito à pessoa e à dignidade humanas, valorização do homem, hierarquia, lealdade recíproca entre empresa e empregados, disciplina, liderança, responsabilidade, postura ética e austeridade.

Além disso, adotou-se como política a admissão do empregado zero quilômetro, que, para a maioria dos empregados, representou o seu projeto definitivo de vida. Outro ponto importante é que a empresa criou condições para que fosse gerado o mito da grande família, traduzido pelo clima de camaradagem e confiança que permeia a organização e pelo comprometimento das pessoas com os objetivos empresariais.

Quanto à questão de a terceirização ter afetado a sua cultura, têm-se os aspectos do conservadorismo presente na empresa e a incorporação dos terceiros à família da empresa.

"Acho que sim, com impacto baixo. Existe a dúvida se o agente externo vai conseguir realizar com eficácia alguma coisa que a gente sempre fez [...] Eu acho que mexe com a cultura, até porque a gente tem uma cultura com aspectos abundantes de conservadorismo” (gerente de O\&M).

"Eu acho que afetou e, se afetou, afetou no sentido de você trazer pessoas de fora, idéias de fora, serviço de fora, maneira de trabalhar de fora, para dentro da sua empresa. Na minha área não, porque é mais gente com nível menos exigido, mais operacional” (gerente administrativo). 
Quanto à empresa ajustar a sua cultura à terceirização ou a terceirização à sua cultura, tem-se que os terceiros, de maneira geral, procuram se adaptar à cultura da empresa.

\section{A Empresa C}

Fundada em 1939, a empresa C posiciona-se no cenário nacional entre as três maiores empresas do setor mineral em volume produzido e em faturamento bruto. Passou por vários momentos de ajustes no seu processo gerencial que, segundo documentos internos, visavam a manutenção da sua competitividade. Para isso foram adotadas medidas como as que seguem: reestruturação das instalações físicas das unidades industriais; mudanças tecnológicas no processo de produção; implantação do Programa de Qualidade Total; alteração da estrutura organizacional com redução de níveis hierárquicos; programas de desenvolvimento gerencial; programas de escolarização básica e de treinamento; reorientação da linha de atuação de recursos humanos; criação da Área de Comunicação Social e certificação pelo ISO 9002.

Segundo dados obtidos, os padrões culturais da empresa podem ser ilustrados pelo direcionamento da sua responsabilidade com os clientes, no sentido de satisfazer às suas necessidades de abastecimento de matérias primas adequadas, priorizando a garantia da qualidade e a agilidade para antecipar-se às suas demandas tecnológicas; com os seus empregados, mediante uma gestão participativa, que leva em conta conceitos como segurança, aperfeiçoamento humano, bem-estar e satisfação; com o meio ambiente, na medida em que a empresa está sempre atenta à necessidade de estabelecer relações saudáveis entre o homem e a natureza, de modo a preservá-la; finalmente com a comunidade, uma vez que a empresa deve criar melhores condições de vida para os municípios onde atua, pelo desenvolvimento sócio-econômico e apoio as iniciativas culturais e pedagógicas.

A empresa contava, em setembro de 1998, com 900 terceirizados e 970 funcionários próprios. Da gestão da terceirização encarrega-se o setor tomador do serviço. Nessa tarefa, tem-se a assessoria do setor de gestão de contratos, que pertence à área de compras da empresa, que se divide em materiais e serviços. Cada área contratante decide e gere a prestação do serviço.

O processo de terceirização na empresa iniciou-se por volta de 1965 com o transporte de produto. Por volta da década de 70, estendeu-se para o transporte de materiais, pessoal e, logo após, para os serviços de conservação, limpeza, vigilância, restaurante e consultorias.

As atividades relacionadas ao transporte, carga e desmonte de minérios estive- 
ram, durante muitos anos, a cargo de terceiros, mas hoje, na sua quase totalidade, é uma atividade da própria empresa; portanto há uma desterceirização desse segmento. Isso ocorreu, basicamente, pela conclusão de que seria mais barato retornar ao transporte próprio. Paralelas a isso, outras dificuldades apontadas dizem respeito ao crescimento do nível de produção e uma grande quantidade de caminhões de pequeno porte, que geravam muitos transtornos, como risco de acidentes, dificuldade no gerenciamento e no controle.

Segundo os entrevistados, o processo de adoção/implantação inicial da terceirização pegou a empresa um pouco despreparada; mas, ao longo do tempo, o processo foi crescendo e sendo adotados ajustes gerenciais no sentido de controlar e acompanhar, de maneira mais sistematizada, a prestação dos serviços.

Quanto aos impactos da terceirização, segundo dados levantados, no início existe certa resistência por parte dos empregados, certo medo; com o tempo, vai sendo acertado.

"Aquelas atividades mais terceirizáveis, quem trabalha no setor, naturalmente já sabe que vai ser sempre um empreiteiro dentro de uma empresa como, por exemplo, a vigilância e conservação. É tão claro que isso é terceirizado, que o empregado já deve ter assimilado" (gerente geral de qualidade e recursos humanos).

Também nessa empresa foi destacada a questão da preferência dos terceiros em se tornarem funcionários da tomadora de serviços.

Os principais problemas enfrentados com o processo de terceirização dizem respeito ao choque cultural entre terceiros e empresa tomadora de serviços, ao aspecto trabalhista, ao clima interno, ao investimento em recursos humanos e ao estabelecimento de uma relação de parceria.

Quanto ao fato de o processo de terceirização afetar a cultura da empresa, tem-se que ele, em alguns momentos, pode reforçar certas políticas da empresa, uma vez que são aceitos certos valores.

"Em alguns aspectos, acredito que sim. Embora existam muitos pontos comuns, sempre haverá pontos técnicos e ideológicos que nem sempre se afinam em todos os sentidos. Você acaba buscando para trabalhar aquele que mais se aproxima do que a gente pede, do que a gente conhece da nossa realidade. Hoje, está mais fácil, porque antigamente havia um punhado de trabalho para essas empresas. Agora, hoje, de um modo geral, você consegue adequar a grande maioria para fazer o que você precisa. Eles entram e não querem sair. Se a empresa está integrada com a gente, ela continua” (assessor da gestão de contratos). 
Ainda assim, há o problema de a terceirização colocar em xeque a confiança e a credibilidade do empregado em valores pregados pela empresa, como a questão da segurança do emprego. As principais mudanças ocorridas na cultura da empresa nos últimos anos dizem respeito a maior abertura, diminuição de níveis hierárquicos, quebra de hierarquia e visão mais holística das pessoas.

\section{O Impacto da Terceirização: Uma Análise dos Resultados NAS EMPRESAS EstudADAS}

A partir dos dados coletados, podem ser destacados alguns pontos: nas empresas A e C há dificuldade de identificação entre terceiros e empregados, ao contrário da empresa $\mathrm{B}$, que utiliza, na sua maior parte, ex-funcionários nas terceirizações de atividades mais especializadas ${ }^{(7)}$.

Para que funcionem de maneira adequada, as empresas necessitam estruturar áreas e designar pessoas responsáveis pelo gerenciamento, acompanhamento e avaliação da prestação dos serviços terceirizados, pois quanto maior o estreitamento de relações entre empresa-mãe e terceiros, melhores têm sido os resultados com a prestação de serviços. Além disso, para que o serviço prestado pelos terceiros seja compatível com o que é demandado pela contratante, é preciso estender os métodos de gestão e de trabalho dessa para aqueles.

Mesmo, a princípio, sendo negado pelos entrevistados o foco no custo, esse é um dos principais determinantes na continuação ou não da terceirização dos serviços. O processo de terceirização causa maior impacto no início da sua implantação, gerando insegurança nos funcionários das empresas. Existem indícios de que a terceirização das atividades de apoio causam menos impactos, uma vez que essas já são, em grande parte, encaradas como terceirizáveis.

Assim, as empresas procuram manter as terceirizações mais em atividades acessórias e de apoio, pois quanto mais próxima da atividade-fim for a terceirização, maiores são os cuidados e problemas devido a fatores como qualidade dos serviços e relação empresa versus terceiros.

Os principais problemas enfrentados pelas empresas em relação à terceirização estão diretamente ligados à qualidade do serviço prestado; quanto mais antigo o processo de terceirização, mais ajustes e necessidade de estruturação de áreas e disponibilização de profissionais responsáveis pelo acompanhamento e avaliação dos serviços prestados. 
As empresas ainda não despertaram para a possibilidade de incluir nos seus sistemas de gestão da terceirização projetos que contemplem questões relacionadas à cultura organizacional e ao relacionamento entre terceiros e funcionários da empresa contratante. Existe preocupação maior quanto aos aspectos quantitativos (custo/benefício) e qualidade (execução) do trabalho dos terceiros. Isso pode ser explicado, principalmente, pela dificuldade encontrada pelos entrevistados das empresas A e C em apontar valores e traços culturais de suas organizações, o que demonstra o fato de não estarem sensibilizados o bastante para essa questão.

Existe forte sentimento por parte dos terceiros de pertencerem às empresas tomadoras de serviços. Isso nos remete à ideia de que a terceirização pode ser considerada como uma das formas de degradação das condições e relações de trabalho no âmbito produtivo atual, principalmente no que diz respeito às atividades que exigem menores índices de qualificação/capacitação profissional. É provável que possam ocorrer futuros problemas com o processo de terceirização, mormente se for ampliado para atividades mais ligadas ao negócio principal das empresas, em razão, entre outros motivos, de colocar em xeque os principais valores defendidos pelas organizações que são: a perenidade, a empresa representar um projeto de vida para seus membros, a lealdade, o orgulho da empresa e a identidade. Nesse caso, haveria grande contradição e inconsistência entre o que é pregado pelas empresas e as ações/decisões que são tomadas.

\section{Considerações Finais}

A terceirização está sendo usada pelas empresas como uma das estratégias de gestão e opção de modernização e posicionamento competitivo no contexto atual e como adequação às necessidades do mercado.

As empresas pesquisadas, conforme dito anteriormente, adotaram o mais difundido conceito para se trabalhar com a terceirização, ou seja, a transferência para terceiros das atividades não inerentes ao seu negócio principal. Isso pode ser verificado pelo baixo grau de terceirização nos setores diretamente relacionados ao seu core business.

A maior preocupação e atenção dos gestores ainda estão direcionadas à qualidade do serviço prestado e à compensação econômico-financeira. Constatou-se que, para isso, são necessárias algumas medidas, como o estabelecimento de verdadeira parceria, uma relação de confiança e investimento no desenvolvimento e na capacitação do terceiro para que ele preste serviço adequado e conforme 
ao que é desejado pela empresa tomadora. Além disso, as organizações têm montado estruturas para a gestão do processo que inclui, basicamente, políticas e procedimentos para contratação e acompanhamento da prestação dos serviços.

A terceirização permite a concentração e especialização da organização em torno do seu core business que, além de lograr melhores resultados, implica produtos de melhor qualidade. Assim, a empresa se concentra em áreas que lhe permitam obter vantagens diferenciadas e que garantam a sua sobrevivência no mercado. O que deve ser considerado como essencial no planejamento estratégico da terceirização, além da preocupação em determinar mudanças nos processos utilizados e na estrutura organizacional, são as formas de resistência, que devem ser alvo de atenção dos órgãos gestores, principalmente no que se refere à cultura organizacional.

O termo cultura organizacional é claro para a maioria dos entrevistados; mas houve alguma dificuldade nas empresas A e C de apontar os seus principais padrões culturais. Foram identificados, nas empresas pesquisadas, traços da cultura brasileira como hierarquização, autoritarismo, paternalismo, improvisação e formalismo.

Além disso, verificou-se também a presença de padrões e valores determinados pela adoção de certas estratégias de gestão, que visam a assegurar a competitividade das empresas no contexto atual como, por exemplo, o foco na qualidade e na preservação ambiental.

Mesmo tendo sido constatada a importância que a cultura organizacional determina no sucesso da terceirização, não foram identificadas medidas concretas que favoreçam e que busquem esse objetivo.

Mesmo assim, pôde-se verificar que os impactos sofridos pela cultura das organizações pesquisadas, nos últimos tempos, advêm das inúmeras mudanças e adoção de novas estratégias de gestão que determinam novos padrões culturais e valores que requerem uma atenção especial ao aspecto da identidade, para que não coloquem em risco o seu êxito.

Enfim, pôde-se constatar, em relação aos impactos da terceirização na cultura organizacional das empresas pesquisadas, que esse processo afeta os valores organizacionais, que, a partir do processo de reestruturação produtiva, tem sido mais concentrado na produtividade, qualidade e competitividade. Esses valores atribuem os significados aos empregados que se ligam às organizações por meio do desempenho de papéis e que, assim, atribuem significado a si próprios, reafirmando os valores da organização. 
Pode-se concluir que existem impactos significativos em certos aspectos da cultura organizacional das empresas pesquisadas; mas esses ainda não chegaram a comprometer a gestão do processo, devido, entre outros fatores, ao pequeno alcance da terceirização de atividades relacionadas ao negócio principal das empresas.

\section{Notas}

${ }^{1}$ A análise da cultura proporciona uma noção abrangente do que ocorre no âmbito organizacional, constituindo-se em discussão de forte tradição no conjunto das reflexões em Administração, podendo-se destacar, entre outros autores, Smircich (1983), Allaire e Firsirotu (1984), Hofstede (1984), Schein (1984), Meyerson e Martin (1987), Pettigrew (1989), Aktouf (1993). No âmbito brasileiro Fleury (1989), Freitas (1991) e Rodrigues (1991), entre outros, deram ênfase e tratamento científico ao tema.

${ }^{2}$ Neste momento privilegiou-se a abordagem de Schein (1984) e Fleury (1989) para o mapeamento das culturas das organizações estudadas, servindo de base para a elaboração do roteiro de entrevistas.

${ }^{3}$ Serviços de apoio: remoção de lixo, limpeza, segurança patrimonial, manutenção predial, serviços jurídicos, serviços gerais, serviços de cobrança, compras não produtivas e contabilidade; serviços de pessoal: restaurante, transporte de pessoal, assistência médica, recrutamento e seleção e rotinas de departamento pessoal; serviços de informática: programação, suporte técnico, análise de sistemas, microinformática, operação/processamento e operação/operadores; área produtiva: manutenção industrial, atividades acessórias à produção e atividades produtivas principais; área comercial: vendas a clientes, assistência técnica, serviços de telemarketing e serviço de atendimento a clientes; área de logística: distribuição física de produtos a clientes, serviços de carga e descarga, armazenagem e movimentação interna de materiais e produtos.

${ }^{4}$ As empresas representadas pelos números 1, 5 e 9 não quiseram participar da continuidade da pesquisa.

${ }^{5} \mathrm{Na}$ empresa A foram entrevistados o assessor de serviços contratados e o assessor de recursos humanos; na empresa B, o gerente de O\&M, o gerente de recursos humanos, o gerente de seleção e desenvolvimento de recursos humanos e o gerente administrativo; na empresa C, o assessor da gestão de contratos e o gerente geral de qualidade e recursos humanos.

${ }^{6}$ Segundo documentos de circulação da empresa.

${ }^{7}$ Esse fato ilustra a idéia de Aktouf (1993) de que nenhuma cultura é possível sem haver identificação dos atores sociais com seus pares, com locais de socialização e sem a interiorização dessa situação enquanto criadora do que são, ou pensam ser, os membros da coletividade. 


\section{ReferênCIAS Bibliográficas}

AKTOUF, O.

O simbolismo e a cultura de empresa: dos abusos conceituais às lições empíricas. In: CHANLAT, J.-F. (Org.). $O$ indivíduo na organização: dimensões esquecidas. São Paulo: Atlas, 1993. v. 3.

\section{ALLAIRE, Y.;}

FIRSIROTU, M.

Theories of organizational culture. Organization Studies, v. 5, n. 3, p. 193-226, 1984.

\section{BATISTA, L. C.}

A terceirização de serviços e seus efeitos nas relações interculturais. In: ENCONTRO ANUAL DA ANPAD, XVIII, 1994, Curitiba. Anais... Curitiba: ANPAD, 1994. recursos humanos.

FARIA, A.

Terceirização: um desafio para o movimento sindical. In: MARTINS, H. H. T. S.; RAMALHO, J. R. (Orgs.). Terceirização: diversidade e negociação no mundo do trabalho. São Paulo: Hucitec, 1994.

FLEURY, M. T. L.

O desvendar da cultura de uma organização - uma discussão metodológica. In: FLEURY, M. T. L.; FISCHER, R. M. (Orgs.). Cultura e poder nas organizações. São Paulo: Atlas, 1989.
FREITAS, M. E.

Cultura organizacional: formação, tipologias e impactos. São Paulo: McGraw-Hill, 1991.

HOFSTEDE, G.

Culture's consequences: international differences in workrelated values. London: Sage Publications, 1984.

\section{MEYERSON, D.;}

MARTIN, J.

Cultural change: an integration of three different views. Journal of Management Studies, v. 4, n. 6, p. 623-647, Nov. 1987.

PETTYGREW, A . M.

A cultura organizacional é administrável? In: FLEURY, M. T. L.; FISCHER, R. M. (Orgs.). Cultura e poder nas organizações. São Paulo: Atlas, 1989.

RODRIGUES, S. B.

O chefinho, o telefone e o bode: autoritarismo e mudança cultural no setor de telecomunicações. Belo Horizonte, 1991. Tese (Livre Docência) - Centro de PósGraduação e Pesquisa em Administração, Universidade Federal de Minas Gerais. 
SÁ, M. P. et al.

Terceirização no processamento final das indústrias farmacêutica e veterinária. In: ENCONTRO ANUAL DA ANPAD, XXI, 1997, Angra dos Reis. Anais... Angra dos Reis: ANPAD, 1997. produção industrial e de serviços. 1 CD-ROM.
SCHEIN, E. H.

Coming to a new awareness of organizational culture. Sloan Management Review, v. 25, n. 2, p. 3-16, Winter 1984.

SMIRCICH, L.

Concepts of culture and organizational analysis. Administrative Science Quarterly, v. 28, n. 3, p. 339-358, Sept. 1983. 